\title{
The Calcium-Sensing Receptor is Upregulated in Post Myocardial Infarct Hearts and Downregulates ANP Expression in Rat Cardiac Myocytes but is Not Expressed in Rat Cardiac Fibroblasts In Vitro
}

\author{
Reza Jabbari ${ }^{1,2, \S}$, Sanela Smajilovic ${ }^{1,2,3, \S}$, Naibedya Chattopadhyay ${ }^{4}$, Stig Haunso ${ }^{1,2}$ and \\ Jacob Tfelt-Hansen ${ }^{*}, 1,2$
}

\author{
${ }^{1}$ Laboratory of Molecular Cardiology, Department of Cardiology, Copenhagen University Hospital, Rigshospitalet, \\ Denmark \\ ${ }^{2}$ The Danish National Research Foundation Centre for Cardiac Arrhythmia (DARC), Copenhagen, Denmark \\ ${ }^{3}$ Department of Medicinal Chemistry, Faculty of Pharmaceutical Sciences, University of Copenhagen, Denmark \\ ${ }^{4}$ Division of Endocrinology, Central Drug Research Institute, Lucknow, India
}

\begin{abstract}
Recently, several reports demonstrated functional expression of calcium-sensing receptor (CaSR) in the heart. Initial reports found the CaSR to be present in the cardiomyocytes, in contrast a recent report have found the CaSR to be present in sheep fibroblasts of the heart. The calcimimetic drug AMG 073 is a pharmacological (allosteric) modulator of CaSR that is in clinical use for the treatment of hyperparathyroidism. Here, we show that CaSR mRNA levels were upregulated in the hearts from rats having myocardial infarction (MI) compared to sham operated rats. Furthermore, we found that in rat cardiomyocytes AMG 073 in the presence of extracellular $\mathrm{Ca}^{2+}$ decreased mRNA levels of atrial natriuretic pre-pro peptide (pre-pro-ANP), which is a marker for cardiac hypertrophy. Surprisingly, CaSR mRNA was not detectable in rat neonatal ventricular fibroblasts (RNVF) by reverse transcriptase PCR. Yet, extracellular calcium exerts a biphasic response in DNA synthesis of RNVFs and AMG 073 seems to suppress DNA synthesis in RNVFs. In addition, calcium and calcimimetic activate MEK/ERK signalling in RNVFs that appears to be independent of CaSR activation. From these results it appears that an additional calcium-sensing mechanism may exist in RNVF. Our findings may be of importance in regards to a potential protective role of calcium and perhaps CaSR against cardiac hypertrophy.
\end{abstract}

Keywords: $\mathrm{CaR}$, mitogene activated kinases, proliferation.

\section{INTRODUCTION}

The calcium sensing-receptor (CaSR) plays a crucial role in the maintenance of systemic calcium homeostasis, and has recently been shown to be involved in the function of cardiovascular system as well [1]. The CaSR belongs to the family $\mathrm{C}$ of the $\mathrm{G}$ protein-coupled receptors, which are also termed seven transmembrane receptors (7TMs) [2]. The 7TMs constitute the largest group of cell surface membrane receptors, and they are the most important targets of currently used drugs. Although the principal physiological ligand of the CaSR is $\mathrm{Ca}^{2+}{ }_{\text {o }}$, the receptor exhibits ligand promiscuity as it binds with several di- or multivalent cations. CaSR agonists are divided into type I and type II. Type I are direct agonists, and the main agonist is $\mathrm{Ca}^{2+}{ }_{0}$, whereas type II are allosteric modulators that change the affinity of receptor to $\mathrm{Ca}^{2+}{ }_{0}$ and other type I agonists. Type II agonists are of two types; i) phenylalkylamine, a small molecule that is termed calcimimetics and ii) L-amino acids

*Address correspondence to this author at the Laboratory of Molecular Cardiology, Department of Cardiology, Section 9312, Copenhagen University Hospital, Rigshospitalet, Juliane Mariesvej 20, DK 2100 Copenhagen O, Denmark; Tel: +4535456738; Fax: +4535456500;

E-mail: tfelt@dadlnet.dk

${ }^{\S}$ These authors contributed equally to the manuscript.
[2]. The calcimimetic drug, AMG 073 is used in the treatment of uremic secondary hyperparathyroidism [3]. Pharmacological modulators that negatively modulate the CaSR actions are termed as calcilytics. The CaSR is a lowaffinity receptor: $\mathrm{Ca}^{2+}{ }_{0}$ produces half-maximal activation of the CaSR at about $3.5 \mathrm{mM}$ in CaSR-transfected human embryonic kidney (HEK-CaSR) cells in vitro [4]. However, the Hill coefficient, a measure of how well the receptor responds to small changes in agonists, is 3-4 in HEK-CaSR cells. This allows the CaSR to detect very small fluctuations in the $\mathrm{Ca}^{2+}{ }_{0}$ such as the small fluctuations of calcium on the cell membrane of the cardiomyocyte as with every heartbeat [5]. Activation of the CaSR elicits diverse cellular signalling, including activation of extracellular signal-regulated kinases (ERKs), p38 MAPK, and c-Jun N-terminal kinase, which account for a variety of distal effects of the receptor, such as proliferation, differentiation, regulation of peptide secretion, and ion channel activity [6-8]. As in the case with many other cell surface receptors, it is as yet poorly understood how the activation of a single receptor type, in this case the $\mathrm{CaSR}$, can result in such varied cellular responses as function of its expression in various tissues/cell types.

Since the initial report in 2003 by Wang et al. showing the CaSR in adult rat myocytes, additional studies have demonstrated the functional expression of the CaSR in the heart $[9,10]$. The expression of the receptor on the cell 
membrane of the cardiomyocytes has widened the role of calcium in the cardiac physiology. And it is possible that $\mathrm{Ca}^{2+}$ is not just the most important intracellular second messenger, but that the extracellular calcium may also exert it's effects through the CaRS and therefore become a extracellular first messenger in the heart. CaSR messenger RNA (mRNA) and protein were detected in both atrial and ventricular myocytes [10]. Challenging isolated ventricular myocytes with $\mathrm{Ca}^{2+}{ }_{0}$ and other type $1 \mathrm{CaSR}$ agonists induced concentration-dependent increases in $\mathrm{Ca}^{2+}{ }_{\mathrm{i}}$ concentrations and intracellular inositol phosphate (IP) concentrations, indicating that the CaSR is linked to the PLC pathway. A positive allosteric modulator of the CaSR, AMG 073, shifted the calcium-IP curve to the left (9). Furthermore, expression of a non-functional CaSR mutant significantly inhibited the $\mathrm{Ca}^{2+}{ }_{0}$-induced IP response, strongly supporting $\mathrm{CaSR}$ as a mediator of the $\mathrm{Ca}^{2+}{ }_{0}$-induced increase in IP levels. Stimulation of the CaSR with AMG 073 induced a reduction in DNA synthesis in neonatal cardiomyocytes, suggesting that CaSR is involved in regulation of the cell cycle. The CaSR-mediated reduction in DNA synthesis observed in our studies was not correlated with changes in cell number, indicating that CaSR protects against cardiac hypertrophy. Recently, increased expression of the CaSR protein in the heart was reported during ischemia/reperfusion [11]. All but one study have pointed towards the calcium-sensing receptor residing on the cardiomyocyte. Surprisingly, Klein et al. recently showed by immunohistochemical staining of tissue sections from a sheep heart that the CaSR protein was expressed in endocardial endothelium, myocardial microvasculature, and cardiac fibroblasts but not cardiomyocytes from a sheep heart [12]. Therefore, we in this study wanted to investigate whether the CaSR expression in the heart is altered post myocardial infarction (MI) to address whether CaSR would also be upregulated during chronic ischemia. To address the possibility of the CaSR residing on the cardiofibroblasts as eluted to by the studies by Klein et al., we next investigated whether the CaSR was expressed in isolated neonatale rat cardiac fibroblasts. Lastly, we investigated the effects of calcium and calcimimetics on the cardiac fibroblasts.

\section{MATERIALS AND METHODS}

\section{Myocardial Infarction (MI)}

Male Wistar rats (Møllegård, Denmark) were used in all myocardial infarct model. The operations were performed during anaesthesia with Fentanyl/fluanisone (Hypnorm) 0.3 $\mathrm{mL} / \mathrm{kg}$ and Midazolam $1 \mathrm{mg} / \mathrm{kg}$ both intramuscularly. The LAD coronary artery was occluded with a 6-0 silk ligature immediately below the left atrial appendage. In the shamoperated animals, the ligature was passed under the artery and removed. Animals were sacrificed 3 weeks after surgery. Only hearts with large transmural infarctions were considered for realtime PCR analysis. The investigation conforms to the Guide for the Care and Use of Laboratory Animals, published by the US National Institutes of Health (NIH Publication No. 85-23, revised 1996). Animals were sacrificed by decapitation. Thereafter, the hearts were excised, rinsed in ice-cold saline, weighed, dissected into left and right ventricles, frozen in liquid nitrogen and stored at $-80^{\circ} \mathrm{C}$ before mRNA extraction.

\section{Rat Neonatal Ventricular Fibroblast (RNVF) Culture}

Rat neonatal ventricular fibroblasts were prepared from 1 - 4 day old neonatal Wistar rats (Møllegård, Denmark). All protocols were in accordance with institutional guidelines and approved by the Danish Animal Experimentation Inspectorate under the Ministry of Justice. The rats were decapitated quickly and the thorax opened. The ventricles were removed from the atria and transferred quickly in a culture dish containing Heparin-MIB-buffer (in 1L: $0.250 \mathrm{~g}$ $\mathrm{Na}_{2} \mathrm{CO}_{3} ; 6,44 \mathrm{~g} \mathrm{NaCl} ; 2.6 \mathrm{~mL} \mathrm{KCl}(1 \mathrm{M}) ; 1.2 \mathrm{~mL} \mathrm{MgSO}_{4}$ $(1 \mathrm{M}) ; 1.2 \mathrm{~mL} \mathrm{KH}_{2} \mathrm{PO}_{4}$ buffer (1M, pH $\left.=7.4\right) ; 9.9 \mathrm{~mL}$ glucose $(20 \%) ; 10 \mathrm{~mL}$ heparin $(5000 \mathrm{IE} / \mathrm{mL}))$. Afterwards, the ventricular tissues were cut with a scalpel into small pieces. The tissue-suspension was replaced by new Heparin-MIBbuffer and transferred into a $50 \mathrm{~mL}$ tube. Then the HeparinMIB-buffer was removed and replaced by $10 \mathrm{~mL}$ TrypsinMIB-buffer (in 1L: $0.250 \mathrm{~g} \mathrm{Na}_{2} \mathrm{CO}_{3} ; 6,44 \mathrm{~g} \mathrm{NaCl} ; 2.6 \mathrm{~mL} \mathrm{KCl}$ $(1 \mathrm{M}) ; 1.2 \mathrm{~mL} \mathrm{MgSO}_{4}(1 \mathrm{M}) ; 1.2 \mathrm{~mL} \mathrm{KH}_{2} \mathrm{PO}_{4}$ buffer $(1 \mathrm{M}, \mathrm{pH}$ $=7.4) ; 9,9 \mathrm{~mL}$ glucose $(20 \%) ; 0.675 \mathrm{~g}$ trypsin (DIFCO); 50mg DNase; $5.5125 \mathrm{~g} \mathrm{MgCl}_{2}, 6 \mathrm{H}_{2} \mathrm{O}$ ). A magnet was added and mixed for 15 minutes at room temperature. The cell suspension was removed and centrifuged for 5 minutes at $1400 \mathrm{rpm}$. The supernatant was then eliminated and the pellet was dissolved in $5 \mathrm{~mL}$ growth-media (Dulbecco's modified Eagle's medium (DMEM), F-12-nutrition media (1:1); 50 $\mu \mathrm{g} / \mathrm{ml}$ penicillin, and $50 \mu \mathrm{g} / \mathrm{ml}$ streptomycin, $10 \%$ foetal bovine serum). At the same time $10 \mathrm{~mL}$ Trypsin- MIB-buffer was again added to the remaining tissue in $50 \mathrm{~mL}$ tubes and mixed for another $15 \mathrm{~min}$. Afterwards, the cell suspension was again removed and centrifuged for $5 \mathrm{~min}$. at 1400rpm, and the pellet was dissolved in the earlier $5 \mathrm{~mL}$ growthmedia. The $5 \mathrm{~mL}$ RNVF suspension was then transferred to a $25 \mathrm{~cm}^{2}$ culture flask and placed at $37{ }^{\circ} \mathrm{C}, 90 \%$ relative humidity, $5 \% \mathrm{CO}_{2}$ for 2 hours to allow the cells to attach to the surface of the flask. Afterwards the media was removed and the cells were washed with $\mathrm{PBS} * 3$ (room temp.) to remove the unbound cells. The growth-media was added and the cells were again placed at $37^{\circ} \mathrm{C}, 90 \%$ relative humidity, $5 \% \mathrm{CO}_{2}$. The cells were split at $80-90 \%$ confluence. Cells were characterized as fibroblasts by morphology and used from passage II - V.

\section{Rat Neonatal Ventricular Cardiomyocyte Culture}

Neonatal ventricular cardiomyocytes were prepared from 1- to 4-day-old neonatal Wistar rats by modification of a previously described method [13]. All protocols were in accordance with institutional guidelines and approved by the Danish Animal Experimentation Inspectorate under the Ministry of Justice. Cells were plated at a density of $5 \times 10^{4}$ cells $/ \mathrm{cm}^{2}$ in minimal essential medium (MEM) supplemented with $1 \%$ L-glutamine, $0.1 \mathrm{mM}$ bromodeoxyuridine, $0.15 \mathrm{mM}$ vitamin $\mathrm{B} 12,1 \mu \mathrm{g} / \mathrm{ml}$ insulin, and $6,250 \mathrm{U} / \mathrm{ml}$ penicillin. Cell culture plates were precoated with $8 \% \mathrm{FCS}$ for $5 \mathrm{~h}$ at $37^{\circ} \mathrm{C}$.

\section{Total RNA Purification and cDNA Amplification}

Total RNA was isolated with Tri Reagent (Molecular Research Center, Cincinnati, $\mathrm{OH}$ ) following manufacturer's instructions. RNA purity and concentration were determined by $\mathrm{A}_{260}$ and $\mathrm{A}_{280}$ measurement. First-strand cDNA was synthesized from 1-2 $\mu \mathrm{g}$ of total RNA with random hexamer 
primers and the Omniscript RT kit (Qiagen, Durham, NC) following manufacturer's instructions.

\section{RT-PCR}

One-step RT-PCR (kit from Qiagen, Santa Clarita, CA) was performed for determining the presence of CaSR transcript(s) using previously published [14], intronspanning primers specific for the rat CaSR, namely sense (bp 1668-1689), 5'-CTATCATCAACTGGCACCTCTC-3' and antisense primers (bp 1929-1950), 5'-TTGTCACAGGC ACTCGCATCTG-3. The control PCR was performed with primers specific for the ubiquitously expressed, endogenous $\beta$-actin gene: 5'-ACCCTCATAGATGGGCACAG-3' and 5'-TGACCCA GATCATGTTTGAGA-3'. We used the following procedure for RT-PCR: cellular RNA was isolated with the Tri Reagent (Molecular Research Centre, Inc, Cincinnati, OH, USA) following the manufacturer's instructions. One microgram of total RNA was mixed with a master cocktail containing RT-PCR buffer, sense and antisense CaSR primers, dNTPs, RNase inhibitor, and an enzyme mixture containing reverse transcriptase (Omniscript and Sensiscript) and HotStart Taq DNA polymerase at the concentrations recommended by the manufacturer (Qiagen) in a final volume of $25 \mu \mathrm{l}$. The temperature-cycle protocol was as follows: $30 \mathrm{~min}$ at $50{ }^{\circ} \mathrm{C}$ for the $\mathrm{RT}$ reaction, followed by denaturation and activation of HotStart DNA polymerase for $15 \mathrm{~min}$ at $95{ }^{\circ} \mathrm{C}$, and PCR amplification $(30 \mathrm{~s}$ at $94{ }^{\circ} \mathrm{C}, 30 \mathrm{~s}$ at $58{ }^{\circ} \mathrm{C}$, and $1 \mathrm{~min}$ at $72{ }^{\circ} \mathrm{C}$ for 40 cycles). A final extension for $10 \mathrm{~min}$ at $72{ }^{\circ} \mathrm{C}$ was performed after the end of 35 cycles. In order to eliminate amplification from contaminating genomic DNA, we omitted RT as a negative control for the RT-PCR. RT-PCR products were fractionated on $1 \%$ agarose gels. The presence of a 283-bp amplified product was indicative of a positive PCR arising from the presence of a CaSR-related sequence within the cDNA. The correct sequence was verified by sequencing (GATC Biotech AG, Germany), using the same primers as for the RT-PCR.

\section{Quantitative Real-Time PCR}

Quantitative real-time PCR analyses were performed with the Rotor-Gene 3000 (Corbett Research, Mortlake, Australia) and the Quantitect SYBR Green PCR kit (Qiagen) following manufacturer's instructions. Primer sequences are listed in Table 1. An internal housekeeping control gene, GAPDH or HPRT, was used to normalize differences in RNA isolation, RNA degradation, and the efficiencies of the reverse transcription. The specificity of each set of primers was ensured by $1.4 \%$ agarose gel analysis and DNA sequence analysis (GATC Biotech, Konstanz, Germany). All mRNAs were quantitated in duplicates and the results were normalized to the content of the housekeeping gene within the same sample.

\section{DNA Synthesis Assay}

Neonatal ventricular fibroblasts were trypsinized and seeded in 12 well plates at a density of $0.5 \times 10^{4}$ cells/well in $1 \mathrm{ml}$ growth medium. The cells were cultured for 48 hours. Afterwards, the cells were starved in serum-free, low calcium-media $\mathrm{Ca}^{2+}$-free DMEM containing $4 \mathrm{mM} \mathrm{L-}$ glutamine, $0.2 \% \mathrm{BSA}$ and $\left.0.5 \mathrm{mM} \mathrm{CaCl}_{2}\right)$ for 6 hours as described previously [15]. Calcium $(0.5-6 \mathrm{mM})$ was added alone or with calcimimetic (AMG073) along with $\left[{ }^{3} \mathrm{H}\right]$ thymidine $(1 \mathrm{ul} / \mathrm{ml} ; 50 \mathrm{uCi} / \mathrm{ml})$ and the cells were cultured again for 24 hours. Incorporation of $\left[{ }^{3} \mathrm{H}\right]$ thymidine was measured by removing the medium and lysing the cells with $0,5 \mathrm{ml} 10 \%$ trichloroacetic acid. The precipitated DNA was dissolved in $0.1 \mathrm{M} \mathrm{NaOH}$ and $1 \% \mathrm{SDS}$, and incorporated radioactivity was measured by counting in a scintillation analyzer (Tri-carb 2900TR, Packard Bioscience, USA).

Table 1. Sequence of the Primers Used in this Study and their Accession Numbers

\begin{tabular}{|c|l|}
\hline Target & \multicolumn{1}{|c|}{ Sequence $\left(\mathbf{5}^{\prime}{ }^{\prime} \mathbf{3}^{\prime}\right.$ ) } \\
\hline \hline 1. CaSR & $\begin{array}{l}\text { (forward) GGGCAACAAAACAAAACTCAAGG } \\
\text { (reverse) ACCTTTACCTGTCCCCTG }\end{array}$ \\
\hline 2. ANP & $\begin{array}{l}\text { CCGGTACCGAAGATAACAG } \\
\text { CTCCAGGAGGGTATTCACC }\end{array}$ \\
\hline 3. SERCA & $\begin{array}{l}\text { CTGATCAGCGGGTGGCTCTT } \\
\text { GTTCATCGCTGCTGACGGTG }\end{array}$ \\
\hline 4. $\beta$-MHC & $\begin{array}{l}\text { CGACTCAAAAAGAAGGACTTTGA } \\
\text { GCGCTCAGCCTCCAGCTC }\end{array}$ \\
\hline 5. GAPDH. & $\begin{array}{l}\text { TTCAATGGCACAGTCAAGGC } \\
\text { TCACCCCATTTGATGTTAGCG }\end{array}$ \\
\hline 6. HPRT & $\begin{array}{l}\text { CGCAAAGTGGAAAAGCCAAGT } \\
\text { GCCACATCAACAGGACTCTTGTAG }\end{array}$ \\
\hline
\end{tabular}

CaSR: calcium sensing-receptor; ANP: atrial natriuretic peptide; SERCA; sarcoplasmatic reticulum $\mathrm{Ca}^{2+}$ ATPase; $\beta$-MHC: $\beta$-myosin heavy chain; GAPDH Glyceraldehyde 3-phosphate dehydrogenase, HPRT: Hypoxanthine ribosyltransferase.

\section{Western Blot Analysis}

For determination of ERK1/2 phosphorylation, the NCF cells were plated at a density of $1 \cdot 10^{4}$ cells $/ \mathrm{cm}^{2}$ on 6 -well plates. After $48 \mathrm{~h}$ in the growth medium, the cells were incubated for $18 \mathrm{~h}$ in serum-free, $\mathrm{Ca}^{2+}$-free DMEM containing $50 \mu \mathrm{g} / \mathrm{ml}$ penicillin, $50 \mu \mathrm{g} / \mathrm{ml}$ streptomycin, 2 $\mathrm{mM}$ L-glutamine, $0.2 \% \mathrm{BSA}$, and $0.5 \mathrm{mM} \mathrm{CaCl} 2$. This medium was removed and replaced with the same medium supplemented with $3 \mathrm{mM} \mathrm{CaCl} 2$ without or with $\mathrm{AMG} 073$ for the indicated periods. Cells were lysed in $62.5 \mathrm{mM}$ Tris $/ \mathrm{HCl}$ (pH 6.8), 2\% SDS, and 10\% glycerol. Protein concentrations were measured with the Bio-Rad DC protein assay and equal amounts of protein $(20 \mu \mathrm{g})$ were separated by SDS-PAGE. The separated proteins were electrophoretically transferred to PVDF membranes (Biorad), blocked with TrisBuffered-Saline (TBS, pH 7.4) solution containing 5\% dry milk for over 1 hour at room temperature and incubated with the primary antibody for 18 hours. Polyclonal antisera against phosphorylated and non-phosphorylated ERK1/2 were purchased from New England Biolabs (Beverly, MA). Afterwards, the blots were washed for three 5-min periods at room temperature with TBST (TBS with $0.2 \%$ Tween 20 ), and then incubated for one hour with a secondary peroxidase-linked antiserum. Blots were then washed again with TBST ( $3 \times 5 \mathrm{~min})$. Bands were visualized using the enhanced chemiluminescence system (Amersham Biosciences).

\section{Data Analysis}


All data was analyzed using GraphPad Prism. Data for realtime PCR and DNA synthesis was analyzed using a oneway ANOVA with Dunnett's Multiple Comparison Test. Data for CaSR expression in MI were analysed by Mann Whitney. A P value $<0.05$ was considered to represent a statistically significant difference unlikely due to chance.

\section{RESULTS}

First, we investigated whether the CaSR expression was altered in the myocardium following myocardial infarction (MI), which would implicate a role for CaSR in remodelling of the heart post MI. A well established rat model of MI was achieved by ligating LAD coronary artery [16]. After sacrifying the rats, mRNA levels of the CaSR in the hearts were compared between the sham operated and MI rats by qPCR. Data show that CaSR mRNA levels were significantly higher $(p<0.05)$ in MI hearts compared with sham group (Fig. 1).

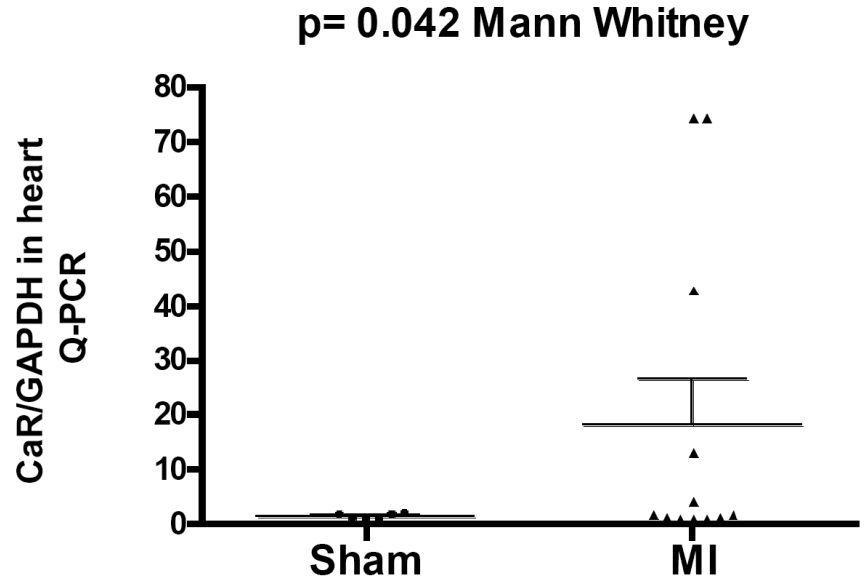

Fig. (1). CaSR mRNA levels were increased in the hearts of post MI, assessed by qPCR. Rats were euthanized and hearts were harvested. mRNA isolation, cDNA synthesis, and qPCR were performed as described in Materials and Methods. GAPDH was used to normalize differences in RNA isolation, RNA degradation, and/or efficiency of the RT reaction. (Sham $=6, \mathrm{MI}=13$, and $\mathrm{P}<0.05)$.

Since we have previously shown that activating the CaSR regulates DNA synthesis in cardiomyocytes, with no effect on cell number [9], and we found CaSR to be upregulated post MI, we hypothesized that CaSR might be involved in hypertrophy. Cardiac hypertrophy is usually associated with an increased expression of atrial natriuretic peptide (ANP) and $\beta$-myosin heavy chain $(\beta-\mathrm{MHC})$, and a decrease in expression of sarcoplasmic reticulum $\mathrm{Ca}^{2+}$-ATPase (SERCA). Rat neonatal cardiomyocytes were incubated overnight with either elevated $\mathrm{Ca}^{2+}{ }_{0}$, AMG 073 (calcimimetic compound), or vehicle. Our data shows that increasing levels of $\mathrm{Ca}^{2+}{ }_{0}$ from $0.5 \mathrm{mM}$ to $2-3 \mathrm{mM}$ did not have any significant effect, whereas $6.0 \mathrm{mM} \mathrm{Ca}{ }^{2+}$ reduced mRNA levels of pre-pro-ANP in NCM (Fig. 2a) $(p<0.01)$. On the other hand, presence of AMG 073 in the presence of both $0.5 \mathrm{mM}$ and $3 \mathrm{mM} \mathrm{Ca}^{2+}{ }_{0} \quad(\mathrm{p}<0.001$ and $\mathrm{p}<0.05$ respectively), decreased mRNA levels of pre-pro-ANP suggesting not only that the CaSR was involved in the reduction of pre-pro-ANP mRNA levels in cardiomyocyte, but also the receptor might have protective action in cardiac hypertrophy (Fig. 2a). No significant changes in the mRNA levels of $\beta$-MHC and SERCA were observed in the cardiomyocytes treated with either elevated $\mathrm{Ca}^{2+}{ }_{0}$ or AMG 073 (Fig. 2b, c).

Next, we investigated the possibility that the increased CaSR expression following induction of MI could be due to the proliferation of neonatal cardiac fibroblasts (NCF). To test this we initially investigated whether the CaSR was expressed in NCF by RT-PCR, using intron-spanning primers. RNA sample from rat kidney served as positive control, yielded an amplified cDNA product of of $283 \mathrm{bp}$ (Lane 4, Fig. 3), expected from bona fide CaSR expressing tissue; whereas the negative control (kidney RNA subjected to PCR without RT) yielded no amplified product. On the other hand, RNA from NCF failed to yield any cDNA product (lane 2, Fig. 3), thereby providing evidence in favor of lack of CaSR expression in NCF as opposed to cardiomyocytes that expressed the CaSR.

With every heartbeat, changes in the levels of extracellular calcium on the external side of the myofibroblasts is caused by the inward calcium current predominantly via the L-type calcium channels [17]. Furthermore, substantial changes in the levels of extracellular calcium are known to occur during MI due to cell necrosis. Therefore, despite lack of CaSR expression in the NCF, we investigated the effect of increasing concentrations of $\mathrm{Ca}^{2+}{ }_{0}$ (from $0.5 \mathrm{mM}$ to $3 \mathrm{mM}$ ) in the NCF, in order to study whether or not $\mathrm{Ca}^{2+}$ modulates DNA synthesis independent of CaSR. Our data revealed that $3 \mathrm{mM}$ $\mathrm{Ca}^{2+}{ }_{0}$ increased DNA synthesis assessed by $\left[{ }^{3} \mathrm{H}\right]$-thymidine incorporation by $30 \%(\mathrm{P}<0.05)($ Fig. $4 a)$. However, at 6.0 $\mathrm{mM} \mathrm{Ca}{ }^{2+}$, DNA synthesis in cardiofibroblasts remained unaltered compared with control. In contrast, the DNA synthesis was reduced by approximately $20 \%$ at to $0.5 \mathrm{mM}$ $\mathrm{Ca}^{2+}{ }_{5}$ plus AMG, though this value was not significant $(\mathrm{P}>$ 0.05). In light of the increasing use of the novel type II CaSR modulator in the treatment of secondary hyperparathyroidism, we also investigated the effect of AMG 073 on NCF. At $3 \mathrm{mM} \mathrm{Ca}^{2+}$, AMG $073(3 \mu \mathrm{M})$ significantly reduced DNA synthesis by approximately $30 \%$ compared to $3 \mathrm{mM} \mathrm{Ca}^{2+}$ alone $(\mathrm{P}<0.01)$ (Fig. 4a). There was no significant effect of AMG 073 on DNA synthesis at 0.5 and $6 \mathrm{mM} \mathrm{Ca}^{2+}{ }_{0}(\mathrm{P}>0.05$ for both $)$. These data suggest that extracullar calcium and surprisingly also AMG 073 regulate DNA synthesis in NCF.

Lastly, we investigated the effect of $\mathrm{Ca}^{2+}{ }_{0}$ (with or without AMG 073) on ERK phosphorylation by Western blotting. MEK1/ERK signalling is known to play an important role in cell cycle regulation. Since we observed that increasing $\mathrm{Ca}^{2+}{ }_{0}$ concentrations induced a biphasic response in DNA synthesis in rat NCM, we investigated whether activation of ERK $1 / 2$ is involved in the process. Treatments of NCFs with $3 \mathrm{mM} \mathrm{Ca}{ }^{2+}{ }_{0}$ for $0-30$ min induced phosphorylation of ERK $1 / 2$ with a maximum at 2-5 min (Fig. 4b). Surprisingly, AMG 073, which reduced DNA synthesis at $3 \mathrm{mM}$ calcium, also activated ERK1/2, maximally at $10-15 \mathrm{~min}$. 
(a)
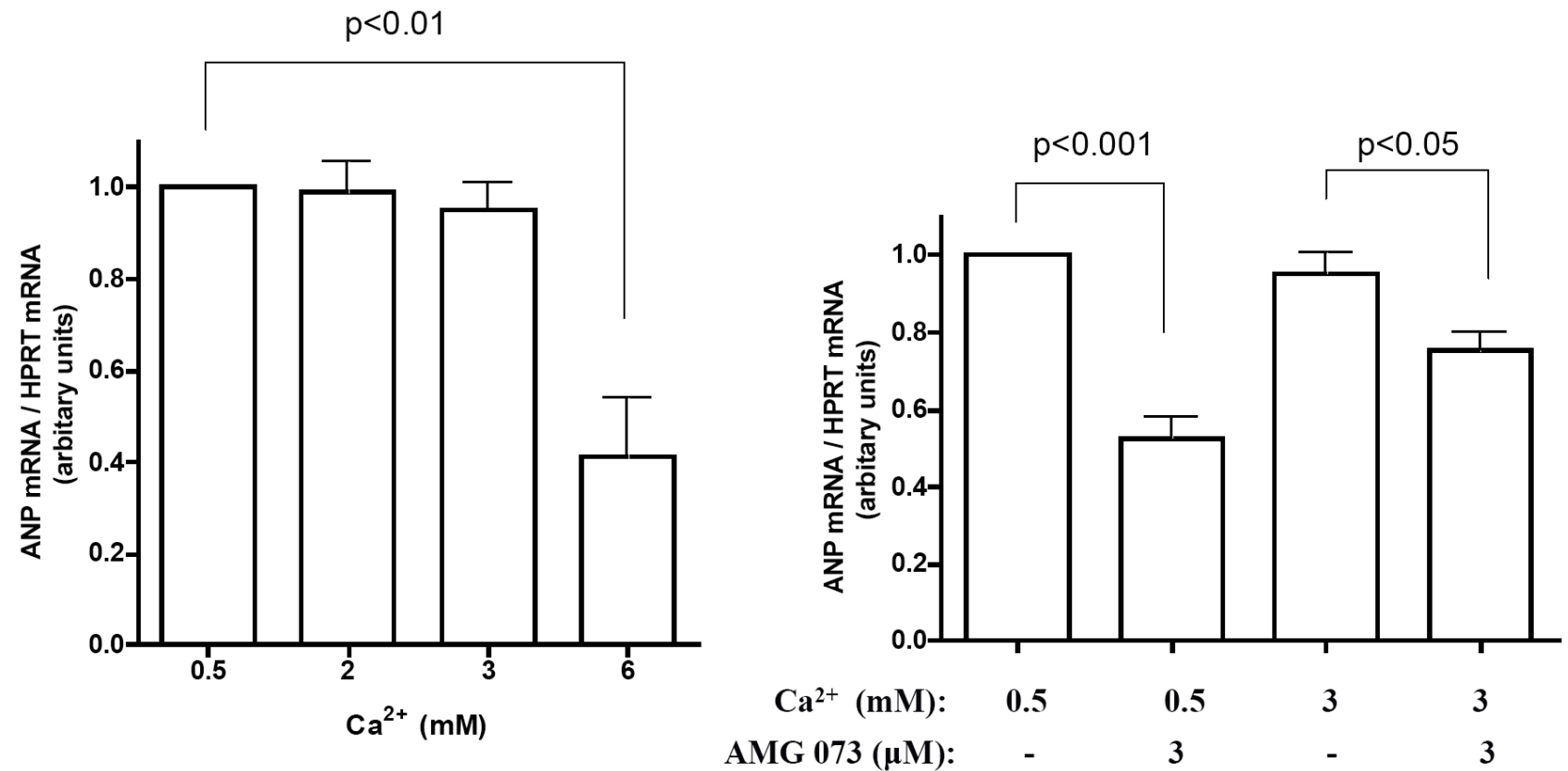

(b)
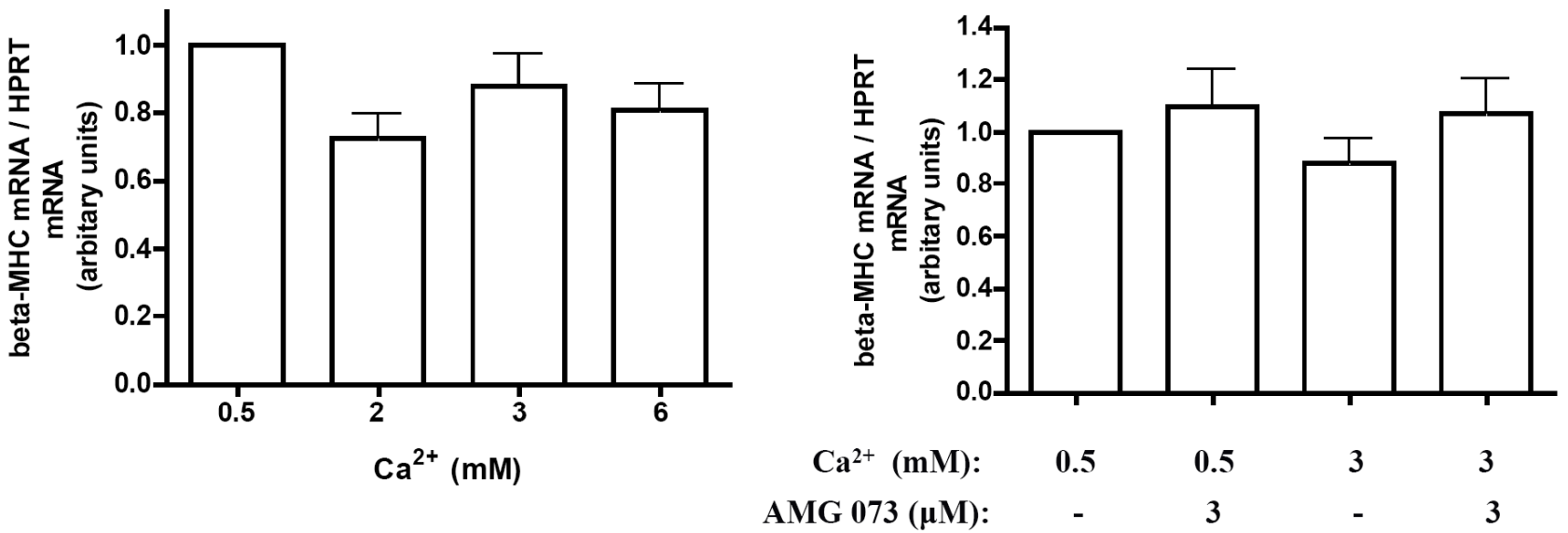

(c)
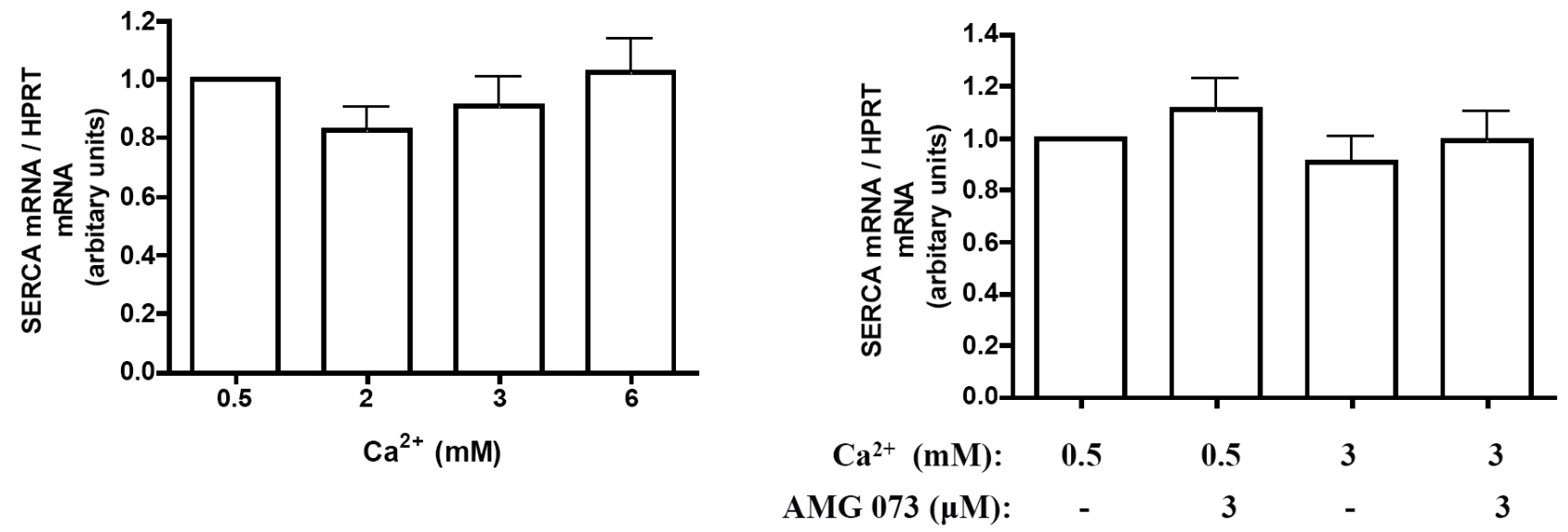

Fig. (2). mRNA levels of pre-pro-ANP (a), $\beta$-MHC (b), and SERCA (c) in rat neonatal ventricular cardiomyocytes assessed by qPCR. NCMs were plated in $60-\mathrm{mm}^{2}$ plates for $96 \mathrm{~h}$ and starved in serum-free media for $24 \mathrm{~h}$. Cells were stimulated in the presence of $\left[{ }^{3} \mathrm{H}\right]$ thymidine at indicated $\mathrm{Ca}^{2+}{ }_{0}$ concentrations or $3 \mu \mathrm{M}$ AMG 073 for $18 \mathrm{~h}$. The data were obtained from ten independent experiments. HPRT was used to normalize differences in RNA isolation, RNA degradation, and/or efficiency of the RT reaction. 


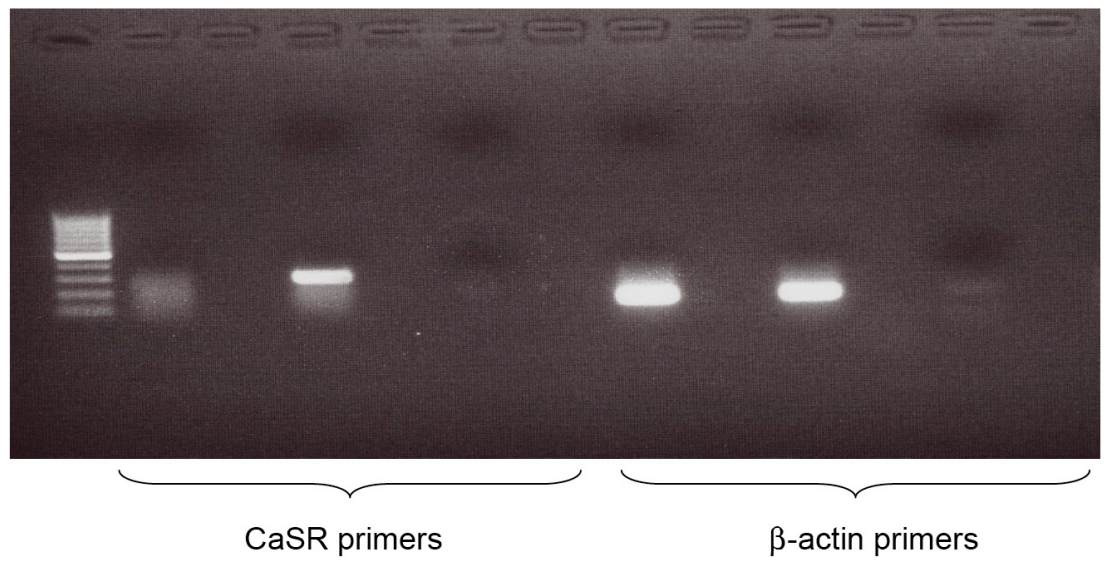

$\begin{array}{lllllllllllll}1 & 2 & 3 & 4 & 5 & 6 & 7 & 8 & 9 & 10 & 11 & 12 & 13\end{array}$

Fig. (3). NCF did not express CaSR mRNA assessed by one step RT-PCR. Lane 1: DNA ladder; 2: NCF (+reverse transcriptase, RT); 3: $\mathrm{NCF}(-\mathrm{RT})$; 4: Kidney (+RT); 5: Kidney(-RT); 6: $\mathrm{H}_{2} \mathrm{O}$ (no template control) 8: NCF (+RT); 9: NCF(-RT); 10: kidney (+RT); 11: kidney $(-\mathrm{RT}) ; 12: \mathrm{H}_{2} \mathrm{O}$.

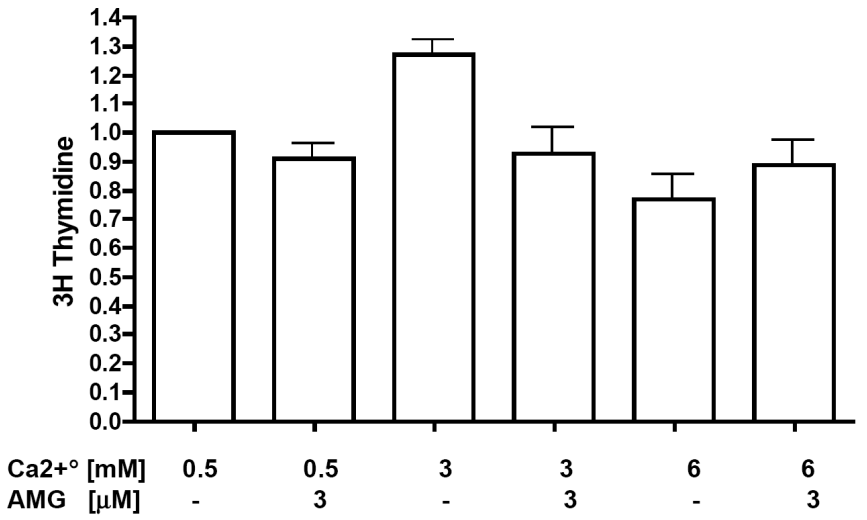

Fig. (4a). Effects of $\mathrm{Ca}^{2+}$ and AMG 073 on DNA synthesis in NCFs. NCFs were plated in 12-well plates for $96 \mathrm{~h}$ and starved in serum-free media for $24 \mathrm{~h}$. Cells were stimulated in the presence of $\left[{ }^{3} \mathrm{H}\right]$ thymidine at indicated $\mathrm{Ca}^{2+}{ }_{o}$ concentrations or $3 \mu \mathrm{M}$ AMG 073 for $18 \mathrm{~h}$. Results are pooled data from 9 independent experiments, each performed in triplicate.

\section{DISCUSSION}

Although there is now strong evidence that the CaSR is present in the cardiac tissue, the function and the location of the receptor in the heart under physiological and pathophysiological conditions is not yet clear [1]. We first investigated whether the expression of the receptor is altered following myocardial infarct by occluding the LAD in Wistar rats [16]. This is a well accepted model to study cardiac hypertrophy and cardiac remodeling post MI [16]. Our data show that the mRNA levels of CaSR were higher in the hearts from rats post MI. This could be due to increased CaSR transcripts either in the cardiomyocytes during hypertrophy or due to increased population of $\mathrm{NCF}$ expressing the CaSR.

We therefore next investigated whether the CaSR is involved in cardiac hypertrophy. Cardiac hypertrophy is associated with, and perhaps in part mediated by, increased expression of several hypertrophic genes, including ANP and $\beta$-MHC [18]. Additionally, SERCA tends to be decreased in several hypertrophy models. We demonstrated that high
Stimuli: $3 \mathrm{mM} \mathrm{Ca}{ }^{2+}$
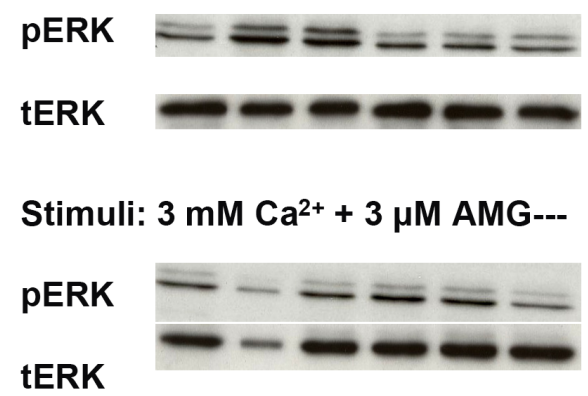

Time (min): $\begin{array}{lllllll}0 & 2 & 5 & 10 & 15 & 30\end{array}$

Fig. (4b). Calcium and calcimimetics activated ERK1/2 phosphorylation in NCF. NCFs were plated in 6-well plates for 48 $\mathrm{h}$ and starved in serum-free medium for $18 \mathrm{~h}$. Cells were stimulated in the presence of $3 \mathrm{mM} \mathrm{Ca}^{2+}{ }_{0}$ alone or with AMG 073 at indicated time points. Upper band - pERK1 and lower band - pERK2. Representative gel picture is shown from 5 experiments with similar results. Total ERK (tERK) was used as the control for equal loading of proteins.

$\mathrm{Ca}^{2+}{ }_{\mathrm{o}}(6 \mathrm{mM})$ as well as AMG 073 decreased mRNA levels of the hypertrophy marker gene pre-pro-ANP, whereas no changes were observed in the expression of two other hypertrophy markers, $\beta$-MHC and SERCA. There are numerous examples of mouse models of cardiac hypertrophy in which classic hypertrophic genes are not expressed as a coherent 'program' [18]. Expression levels of ANP could be independent of the other hypertrophy markers. The observed decreases in the expression of pre-pro-ANP mRNA levels combined with downregulation of DNA synthesis by the CaSR activation in cardiomyocytes, previously reported [9], suggest that the receptor might be protective against hypertrophy. These findings are contrary to the suggestion of CaSR promoting hypertrophy by promoting apoptosis of neonatal rat cardiomyocyte and Angiotensin II-induced hypertrophy $[19,20]$. However, these studies, unlike our present study did not include type II CaSR agonist such as AMG 073 and hence the specificity of CaSR response in cardiomyocyte remained uncertain. 
Next, we studied the expression of CaSR mRNA in NCF, the most abundant cell type of the heart. In sheep, CaSR immunoreactivity have been shown in aortic and myocardium fibroblasts [12]. Fibroblasts from other species and organs have been shown to express the CaSR including colonic myofibroblasts, NIH 3T3, and Rat-1 fibroblasts [2123]. Our results from RT-PCR using RNA samples from NCF failed to detect CaSR mRNA. Furthermore unpublished data from our laboratory also failed to detect CaSR mRNA in a human cardiac fibroblast cell line. Whether CaSR expression in fibroblasts is dependent on organs from which they are derived or a function of species variation remains to be determined.

Despite our failure to detect CaSR transcript in NCF, we considered it interesting to investigate the effect of $\mathrm{Ca}^{2+}{ }_{0}$ on DNA synthesis, as calcium levels on the surface of a cardiac fibroblast change with every heartbeat. Stimulating the NCFs with $3 \mathrm{mM} \mathrm{Ca}^{2+}$ o promoted DNA synthesis in these cells, whereas at $6 \mathrm{mM} \mathrm{Ca}^{2+}{ }_{0}$ DNA synthesis was decreased. On the other hand, presence of AMG 073 abolished the stimulation of DNA synthesis by $3 \mathrm{mM} \mathrm{Ca}^{2+}{ }_{0}$. These data suggested to us that the effects of $\mathrm{Ca}^{2+}{ }_{0}$ and AMG 073 are different and likely act on different cellular targets. Different kinetic of ERK1/2 activation by elevated $\mathrm{Ca}^{2+}{ }_{0}$ and AMG 073 further corroborates this argument. In addition, the biphasic nature of DNA synthesis by elevated $\mathrm{Ca}^{2+}{ }_{0}$ was observed in NCF (having no CaSR expression) as well as in cardiomyocytes (expressed CaSR mRNA) further confirmed lack of CaSR' role in mediating DNA synthesis in these two cell types from heart [9].

Taken together, our data show that CaSR expression is increased in cardiomyocytes following MI with attendant reduction in pre-pro-ANP mRNA levels. The effects of elevated $\mathrm{Ca}^{2+}{ }_{0}$, on the other hand in NCFs appear to be independent of CaSR. Future studies should address whether or not stimulation of the CaSR during a hypertrophic response protects from an increase in cardiomyocyte size. As AMG 073 is clinically used in the treatment of uremic secondary hyperparathyroidism [3], our data suggest that in addition to signaling via the CaSR, similar to that expressed in parathyroid gland, AMG 073 could also via other CaSR'like' molecule for example the recently deorphanised 7TM GPRC 6A.

\section{REFERENCES}

[1] Smajilovic S, Tfelt-Hansen J. Calcium acts as a first messenger through the calcium-sensing receptor in the cardiovascular system. Cardiovasc Res 2007; 75: 457-67.

[2] Tfelt-Hansen J, Schwarz P, Brown EM, Chattopadhyay N. The calcium-sensing receptor in human disease. Front Biosci 2003; 8: s377-90.

[3] Urena P. Use of calcimimetics in uremic patients with secondary hyperparathyroidism: review. Artif Organs 2003; 27: 759-64.
[4] Quinn SJ, Ye CP, Diaz R, et al. The Ca2+-sensing receptor: a target for polyamines. Am J Physiol 1997; 273: C1315-23.

[5] Hofer AM, Curci S, Doble MA, Brown EM, Soybel DI Intercellular communication mediated by the extracellular calciumsensing receptor. Nat Cell Biol 2000; 2: 392-8.

[6] Tfelt-Hansen J, Yano S, John MR, Smajilovic S, Chattopadhyay N, Brown EM. High calcium activates the EGF receptor potentially through the calcium-sensing receptor in Leydig cancer cells. Growth Factors 2005; 23: 117-23.

[7] Tfelt-Hansen J, Ferreira A, Yano S, et al. Calcium-sensing receptor activation induces nitric oxide production in $\mathrm{H}-500$ Leydig cancer cells. Am J Physiol Endocrinol Metab 2005; 288: E1206-13.

[8] Ye CP, Yano S, Tfelt-Hansen J, et al. Regulation of a Ca2+activated $\mathrm{K}+$ channel by calcium-sensing receptor involves p38 MAP kinase. J Neurosci Res 2004; 75: 491-8.

[9] Tfelt-Hansen J, Hansen JL, Smajilovic S, Terwilliger EF, Haunso $\mathrm{S}$, Sheikh SP. Calcium receptor is functionally expressed in rat neonatal ventricular cardiomyocytes. Am J Physiol Heart Circ Physiol 2006; 290: H1165-71.

[10] Wang R, Xu C, Zhao W, et al. Calcium and polyamine regulated calcium-sensing receptors in cardiac tissues. Eur J Biochem 2003; 270: $2680-8$.

[11] Zhang WH, Fu SB, Lu FH, et al. Involvement of calcium-sensing receptor in ischemia/reperfusion-induced apoptosis in rat cardiomyocytes. Biochem Biophys Res Commun 2006; 347: 87281 .

[12] Klein GL, Enkhbaatar P, Traber DL, et al. Cardiovascular distribution of the calcium sensing receptor before and after burns. Burns 2008; 34: 370-5.

[13] Busk PK, Bartkova J, Strom CC, et al. Involvement of cyclin D activity in left ventricle hypertrophy in vivo and in vitro. Cardiovasc Res 2002; 56: 64-75.

[14] Smajilovic S, Hansen JL, Christoffersen TE, et al. Extracellular calcium sensing in rat aortic vascular smooth muscle cells. Biochem Biophys Res Commun 2006; 348: 1215-23.

[15] Tfelt-Hansen J, Chattopadhyay N, Yano S, et al. Calcium-sensing receptor induces proliferation through p38 mitogen-activated protein kinase and phosphatidylinositol 3-kinase but not extracellularly regulated kinase in a model of humoral hypercalcemia of malignancy. Endocrinology 2004; 145: 1211-7.

[16] Strom CC, Kruhoffer M, Knudsen S, et al. Identification of a core set of genes that signifies pathways underlying cardiac hypertrophy. Comp Funct Genomics 2004; 5: 459-70.

[17] Tfelt-Hansen P, Tfelt-Hansen J. Verapamil for cluster headache. Clinical pharmacology and possible mode of action. Headache 2009; 49: 117-25.

[18] Dorn GW, 2nd, Robbins J, Sugden PH. Phenotyping hypertrophy: eschew obfuscation. Circ Res 2003; 92: 1171-5.

[19] Sun YH, Liu MN, Li H, et al. Calcium-sensing receptor induces rat neonatal ventricular cardiomyocyte apoptosis. Biochem Biophys Res Commun 2006; 350: 942-8.

[20] Wang LN, Wang C, Lin Y, et al. Involvement of calcium-sensing receptor in cardiac hypertrophy-induced by angiotensinII through calcineurin pathway in cultured neonatal rat cardiomyocytes. Biochem Biophys Res Commun 2008; 369: 584-9.

[21] Hobson SA, Wright J, Lee F, McNeil SE, Bilderback T, Rodland KD. Activation of the MAP kinase cascade by exogenous calciumsensing receptor. Mol Cell Endocrinol 2003; 200: 189-98.

[22] Pacheco, II, Macleod RJ. CaSR stimulates secretion of Wnt5a from colonic myofibroblasts to stimulate CDX2 and sucrase-isomaltase using Ror2 on intestinal epithelia. Am J Physiol Gastrointest Liver Physiol 2008; 295: G748-59.

[23] Hoff AO, Cote GJ, Fritsche HA, Jr., Qiu H, Schultz PN, Gagel RF. Calcium-induced activation of a mutant G-protein-coupled receptor causes in vitro transformation of NIH/3T3 cells. Neoplasia 1999; 1: 485-91. 